\title{
Education Democracy - The Spiritual Equality Encounter between Teachers and Students
}

\author{
Ming Fan $^{1,}$ a \\ ${ }^{1}$ Shaanxi Xueqian Normal University, Faculty of Pre-School Education, Xi'an, Shaanxi, China, \\ 710100 \\ ${ }^{\mathrm{a}}$ email,
}

Keywords: Teacher, Teachers' Authority, Education Democracy

\begin{abstract}
In the practice of education, teachers' authority has controlled the teaching process. This research attempts to analyze the formation process of teachers' authority in the teacher's role expectation and stress from the sociological perspective. And we also put forward the views that that education democracy is a spiritual equality between teachers and students, we should realize that the student is "people", who is "the developing people" and "the developing people of learning actively".
\end{abstract}

\section{Introduction}

Some scholars have proposed "nature of a society in education is first reflected by the nature of the relationship between teachers and students, and education in a democratic society should also be reflected in the first democratic teacher-student relationship." [1] Thus, when we talk about democracy in the field of Education, the first thing people think of is a democratic inter-teacher-student relationship. Teachers and students are no longer merely freeze the subject and object of education, teachers and students when guided learning between subjects is considered the essence of education when [2], ie, hope to reach a spiritual equality between teachers and students meet in genuine democratic relations. However, teachers' authority prevailing Chinese educational practice, teachers and learners may become equal dialogue advocate it?

\section{The Authority of Teachers Unifying the Teaching Process}

Education is an extremely large, complex mixture, sometimes it seems that we simply do not know in the end what is education, but we can put education as a social process, and classroom teaching is the concentrated expression of social education. In the traditional classroom, the teacher's authority governs almost the entire teaching process.

In the eyes of teachers, students are generally treated as a "whole" to deal with, it does not matter "who" are educational activities directed "objects" only. Education teaching activities starting point for educators is in accordance with the statutory requirements of the course, teachers will be educated incorporate some predetermined orbit, with a series of "ideal" requirements and rules requiring individual according to a fixed pattern to perceive, think and action, awareness conclusion first determined prior to the student's awareness activities, which suppress the formation of consciousness, which conform to the socialization of the "commonality" requirement. "Collective is considered eternal purposes, but the individual is a means, a tool, because it can strengthen the character of obedience, of unjust social phenomenon not protest, but again many people need to suppress the lowest level." [3]

Select the object from the point of view, and light weight program needs. China's current education model is a vision of the personal status regulations or accepted as educational purposes, and to implement it through education. In fact, this idea is a ready state, from adult society collective forecast for the future, regardless of the student as a "human" exists, do not consider each individual's unique needs, and in some kind of "legal procedures" (in accordance with the syllabus conducting educational activities to promote the next step specified) premise. Dewey has been questioned, "People have a tendency to consider adult favorite things, regardless of the ability of the 
educated, put them as the purpose of education. There is also a possible tendency to raise the monotony of purpose, a special personal neglect capacities and needs, forget all knowledge is a specific person at a specific time and place available. "[4] if the setting for educational purposes, with no thought of the educated individual special needs, this approach only domesticated a batch no creativity, no personality "biological."

The main responsibilities of teachers in the classroom are set up in accordance with his earlier "frame" to manage and control the teaching process. Based on this, the teacher in teaching activities usually have absolute authority, and sometimes, people even through evaluation of teacher education with the ability to control the teaching process to measure the level of professionalism of teachers. Therefore, teachers generally expect students to control their own dominant or recessive behavior to "obey" response, of course, which also includes students for so-called "democratic" their take "equality" or "cooperation" of interaction obedience.

We do not deny the teaching activities in teachers' authority also have some positive effect, even a necessary prerequisite for the smooth development of teacher education and teaching activities. But if too much emphasis on the authority of teachers, and students will be entirely in the passive or dominant position, it does not conform to the requirements of modern education. Therefore, we need to analyze the process of teaching teachers lack democratic consciousness reasons.

\section{The Reason for the Lack of Democratic Consciousness of Teachers}

Authority over teachers' awareness, sense of democracy constrained by its lack of control from the subjective in some respects, but the root causes of this subjective control produces little or not depends on the level of individual thinking, but by their social environment in which as well as its role identity constraints. Social education teachers face determines the complexity of the environment, the teachers in a complex social environment in which they experience the essence of the role is a complex role expectations, but hovering between role expectations and role strain caused by the authority of teachers Consciousness continue to strengthen, it is the real cause of their lack of democratic consciousness.

Teachers Have to Deal With Various Expectations for Their Social Roles. In teaching activities, teachers Language in Society and Culture "historical context", as well as its exposure to classroom "present scenario" which determines the teachers' scene of complexity. This complex scenario decided, teachers have to face the "teacher" from a wide range of social roles and expectations of their own produce.

The first is the social and cultural expectations of teachers. Evolved all the way from the primitive society, the increasing complexity of human social groups, people get a lot of knowledge and skills, these elements or, in fact, according to the subjective consciousness or groups, it will depend on the standard that people experience accumulated ideas and thus make the content of social life has been more clearly stated, mainly through textbooks, teaching aids and other carriers, to teach the younger generation to continue the need of group life. In order to allow students in a limited time, to grasp the accumulation of human civilization for thousands of years the essence of the teacher as if social and cultural identity of the successor, on behalf of the national socio-cultural dissemination, education exert influence on students.

Followed by the statutory curriculum for teachers expect. When the "Syllabus" dressed "legal course" coat play their own important role in the education process, the nexus between teaching and social groups they reflect habits and ideals are so camouflaged shelter, became mere knowledge of the existence of some kind of group interests, but only for the students to master the teaching material itself rather than its social value was given. Course became a purposeful, planned, organized the transfer process, and as a teacher curriculum implementers were given the "tools" role qualities, characterization of their "conversion" system culture, "society representatives "identity exercise of the privileges conferred by the system, and look forward to the students for their demeanor, respect the concept of attitude, behavior and other imitation through education and teaching activities. In this sense it can be said that teachers in the classroom teaching students actually act as "behavioral paradigm" role. [5] Under the influence of such expectations, the 
teacher's educational autonomy enjoyed by them as well as the evaluation of students the right to self-understanding, continue to weaken the students 'independence, "and to strengthen the students' teacher to sex ", and through a variety of written and unwritten" system "to dominant or recessive manner the role of teachers over the release function.

Third is the students' expectation for teacher. "Student teachers fear originated in the wisdom of life for teachers and educational wisdom surprise, it is not just a feeling or an understanding way, is the contrast greater sense of their own insight." [6] With the advent of the information age, although the way the students acquire knowledge diversification has not only limited to teachers, but because of life experience, has cognitive differences, the ability to understand other aspects of the education process teachers still maintain its position of "knowledge leaders" unshakable. Teachers and students to follow the subject, leading to its "parent" of the sense of control, fear of student any irregularities established norms of behavior, and all students will have under their control and supervision, and such behavior regarded as the care of student performance, to strengthen its authority identity and status. Finally, looking forward to "academic" Teachers belongs to its "elite culture". The so-called "elite" means that due to the advantage in the social and cultural background, political position or economic resources, and to be "culled few" or "excellent character."

Teachers Have to Go Through Various Tensions for Their Social Roles. Teaching is a process between "teacher - student - course" three levels of spiritual energy transformation. It is in this embarrassment caused by their social roles, teachers continue to experience a variety of tensions and sometimes we can clearly feel the teachers in a negative, defensive and even the state.

First, the tensions between statutory curriculum and social cultures. Contains legal course is the "power" of the universal, standardized cultural patterns in the role of institutions. As curriculum support materials, supplied in the past collective experience to contribute to the desired content of social life now, which is the meaning of existence lies. The development of increasingly complex social life, teaching materials necessary to supply information on the quantity and quality have increased. But with the current rapid development of information society, the mass media is to provide students with a variety of lifestyles and value systems of different sectors, sometimes for commercial purposes, even after rendering is a choice, twisted scene from Social picture of this composition is often not truly reflect reality. This has resulted in students' rationality institutional culture or teachers passed standardizing the cultural legitimacy of doubt or even deny. Teachers' authority as the institutional culture, its identity and status of the system is given, in order to ease the conflict between secular culture and institutional culture, maintaining institutional culture of "legitimacy", it is necessary to take some measures to control the students recognize and enforce within specification of this culture.

Secondly, the legal tension between curriculum and teacher status. Makers, teachers are not statutory curriculum, the statutory curriculum development is a complex of rights game process by a "knowledge occupants' cultural capital, as" rights holders "political capital, and as a" financial investment by "economy capital Group constituted "consultations" made. However, the teacher is a statutory program implementers, such conflicts lead to the identity of the social role of the obvious. "He (she) came from different social classes, with different family and cultural background, trained in different schools, it carries a different ideal of education", [7] However, the text of the statutory curriculum cannot be teachers of the difference between fully incorporated. When teachers follow the abstract and universal individual and local sexual encounter legal course, the life of the world will be showing nervous. In the education scenario, this tension is normal existence. When teachers feel with a personal capacity cannot be solved, in order to coordinate the implementation of the process of legal contradictions and conflicts curriculum and their own social roles between its carrying out teaching activities, instinctively showing a tight cover or tend to maintain strong authority.

Again, the statutory curriculum and student needs tensions between. In the process of generating the statutory curriculum, teachers not only continue to be marginalized, and the students' needs are increasingly not being taken seriously. Selected courses often presented in some narrow class know "living" as the standard, in the course "accept" the education of students, as long as its predecessor 
phased goals, have some literacy skills, then coupled with the need to master a certain extent, muscle dexterity agile skills to cope with life in the future to prepare. This time the "student" Most simply age for the sector, is planning was stepped forward. However, students who are conscious of having a body, each person's consciousness is purely personal, and every student with their own "body" as the substance boundary marked himself with other individuals in different psychological uniqueness. This uniqueness is not only caused by the imbalance of student differences in physical development, but also by the cultural differences from different backgrounds living brings.

Strengthening the Sense of Authority of Teachers Hovered in Role Expectation and Tension. Hovering in the social role of expectation and tension, teachers strive to use their authority to coordinate the complex relationship with the curriculum, among students, but also continue to use their professional autonomy and the right to evaluate students to strengthen their coordination in the process of the authority of consciousness to maintain and consolidate their position of authority.

On the one hand, teachers use the professional autonomy to reconstruct the curriculum knowledge. Teachers' professional autonomy is one of the teaching profession professional reflect signs of existing education laws and administrative regulations clearly stipulates the right to education teachers enjoy first is the "right to education." Thus, the framers of teachers, although not a statutory curriculum, but it is the legal representative of the course have been given the rights and obligations of Curriculum.

On the other hand, teachers use the student evaluation system to maintain the smooth development of teaching and learning activities. One of the right to education for students of management rights, but also China's current education laws and administrative regulations clearly define the main teachers enjoy. Teachers in the interpretation of this right in order to "exercise power on behalf of the State," the body itself, although experiencing tension between the legal and socio-cultural curriculum, and students need their own identities, but still have to be used in the role expectation the rights conferred by controlling the students make teaching activities smoothly pursued, and this control can be both dominant, through the educational system and regulations to constrain the behavior of students, such as school hours, classroom discipline; it may be hidden nature, through the teaching process of reallocation of resources to regulate the behavior of students, such as class seating layout, and so the chance to speak in class. This behavior is controlled in the manner or method exists, but most directly in the education process is the most effective means of control is the evaluation, teacher evaluation by students, can influence the perceptions of students, and even affect students the direction of development. Therefore, the evaluation of a student becomes teacher to realize their authority may be practiced, actionable way.

\section{The Possibilities to Establish Democratic Relationship between Teachers and Students}

Above us from a sociological perspective, we analyze the formation process of wandering in the role expectations and tensions in the consciousness of the authority of teachers, and in the process trying to sort out how teachers use their professional autonomy and the right to evaluate students, continue to strengthen their own position of authority. In this connection we cannot deny the authority of teachers and even criticize it? The answer is not absolute. In order to maintain influence in the teaching of teachers, teachers in the teaching process should correctly treat their authority. However, this authority should be established only on the basis of teacher's charisma and good professional quality on, otherwise, the authority of teachers is an institutionalized, formal external authority. Real democracy equality between teachers and students is a spiritual encounter, as a teacher, to be formed - students are "people" and "the development of the people" and "active learning in the development of people," the consciousness, in thought on an equal footing with students to expand two-way interactive communication and dialogue.

Students Are "People". We want students to have the former "human" perspective at the education and curriculum. The reason why people different from "other", because people tend to come out constantly adapt to the environment resulting in the transformation of the subjective awareness of the environment during the social, and the composition of society not because people were in the same place, but because we have each other interworking purpose, consciousness, 
emotion and even behavior. Development of human society depends on psychological factors such mutual maintain these mental factors arise from interpersonal contact and communication with each other, but it is an effective link between education and communication of important channel for people to complete the inter-consciousness longitudinal and transverse propagation heritage, acquire knowledge and skills through education. However, with the progress of history, accumulation and precipitation of human culture, education of minors has not "routine transfer" can be completed, the official in charge of cultural and educational institutions, cultural transmission school attendant. From then on, cultural expression and transmission is increasingly dependent on the text, so people understand the mission of the school from the original intention of education human socialization, to teach literacy. Therefore, teachers should first student teaching is seen as ideologically on an equal footing with their "people", it is worthy of respect, understanding, dialogue people. Teachers must recognize that the student is the main body of the "people", people are different, in the teaching process and they have their different learning objectives and methods to the individual as the basic unit of self-construction of the learning experience. "Being the educational activities of students' authoritarian personality, dignity neglected and student initiative and creativity are suppressed, and thereby generate apathy or alienation from the teacher-student relationship with the teachers and students psychological. Clearly recognized division student relationship is a 'people - people relations, teachers and students who are independent of each other, which is the basis of the teacher-student relationship is formed democratic "[8]

The Students Are "Developing People". We have to understand the students' development of the people. "Social or environment is not static or absolute, it is always change and no ultimate environment. In society there is a continuous renewal and reorganization, it must also be updated with the development and reorganization of their era has had experience. To adapt to the environment and people, we must first develop the ability to adapt to the social needs of those constantly changing. Because the body has a consciousness, every student has a "personality", and this personality is neither innate nor immutable, it is under constant contact with all kinds of relations with the run-force gradually, as a result of the stage is the main human and social environment interaction. Education is to enhance the quality of life of students in social activities. The essence of education is not only the people adapt to the current environment, but also continue to develop them to meet the future will face environment. Therefore, the people as the continuous development of the education of the individual, the people liberated from conventional thinking and impulsive behavior domination, making them to plan for their future, and to adjust and modify the plan in the ongoing development process, final to achieve the original purpose through their own efforts, so that the individual's ability to get promoted. Therefore, the value of education and respect, that is the belief that every student, seen as a changing of individual development, in order to allow them to develop feelings of adults, an opportunity to reflect and act.

The Student Is "The Developing People of Learning Actively". We believe that students should be "active learning in the development of people." Dewey has proposed that education is not to let the children straight into the existing knowledge and it cannot be injected into the existing textbooks to children by teachers. Students receive education aims not only to "receive and protected," teachers must not only do the national legal course "transmitters", in addition to teach students the most basic, the most important knowledge, teachers should also stimulate students' independent , proactive thinking, so that students learn to "giving and sharing." Education allows students from the self-awareness, to focus on other than their own experience and the experience, education for human learn more than the real world and richer world offers the possibility, which is a life beyond the finite infinite possibilities. The "incompetent teachers forced students to receive real knowledge and a good teacher is to teach students seek true knowledge." [9] Therefore, look forward to equal education for democracy meet inter-spiritual teachers and, with spiritual equality between teachers and students, to encourage students to spiritual freedom. Free Spirit refers to the people in a particular environment, driven by individual initiative, so that the consciousness of the thinking subject freedom. The pursuit of spiritual freedom in education, it is hoped consciousness of students can play a role in learning, active observation, independent thinking, visionary found that 
by adapting to various conditions and the environment, internalized, self-adjustment, and thus the results make a reasonable prediction, in order to promote individual autonomy, active development. Therefore,

\section{Conclusions}

When discusses democracy in education, we have to mention Dewey, he pointed out in "Democracy and Education" that the "School is such a purely individualistic between learning and social action as well as freedom and social control the most distinctive institution fictional opposition performance."[10] Thus, in the field of education, we do not exclude the authority when discussing democracy, in a sense," There is no authority, there is no education relationship established, there is no good teacher-student relationship, the "key" is that the teachers how to use psychology, institutionalized authority or knowledge to achieve educational purposes. "[11] Therefore we look forward to the teacher can correct understanding of the nature of the students - the students are "people" and "the development of the people" and "active learning in the development of people," Keep scientific reasonable view of students, even in the face of role expectations and role strain, we can also have more clearly defined curriculum, educational philosophy and establish a good teacher-student relationship on this basis. Make classroom teaching truly become the activities which can glow vitality of students, stimulate students' creative thinking, teachers can use the idea of democracy, openness, cooperation between teachers and students to create a way to meet the spiritual equality of opportunity!

\section{Acknowledgements}

Fund Project: Shaanxi Provincial Educational Department Special Research Project (2013JK0417): Exploration of the Dialogue Essence of Kindergarten Teacher and Children from "Non-Expect Answers".

\section{References}

[1] Shi Zhongying Education concept of democracy. - A Critical Research [J] Peking University Education Review, 2009 (10).

[2] Hao Wenwu Philosophy of Education [M] Beijing: Education Science Press, 2009.

[3] Personality Development Fu-owned cloud. Teachers and students of democratic consciousness[J]. Journal of Hunan Normal University, 1989, (1)

[4] Zhao Xianglin, Wangcheng Xu compiled Dewey Education of the election [M] Shanghai: East China Normal University Press, 1981.

[5] Wukang Ning. Classroom Teaching Sociology[M]. Nanjing: Nanjing Normal University Press, 1999.

[6] Ye Lan teacher teacher's role and the development of new exploration [M] Beijing: Education Science Press, 2001.

[7] Teachers often sub-Hui: Crevice actors [J] contemporary teacher education, 2008, (1).

[8] Zhang Nan principles of education [M] Guilin: Guangxi Normal University Press, 2007.

[9] [de] Diesterweg Yuan Yian translation German Teacher Training Guide [M] Beijing: People's Education Press, 1990: 123.

[10] [US] John Dewey Wangcheng Xu translated • Democracy and Education [M] Beijing: People's Education Press, 2001: 319.

[11] Shi Zhongying Education concept of democracy. - A Critical Research [J] Peking University Education Review, 2009 (10). 